\title{
A New Human Anatomy Teaching Mode Combining Virtual Anatomy System and Dissection to Promote Active Learning and Improve Learning Efficiency.
}

$\mathrm{Na}$ Chen

Third Military Medical University

Bin Fang

Third Military Medical University

Wen Tan

Third Military Medical University

Ying Li

Third Military Medical University

$\mathrm{Na}$ Luo

Southwest Hospital

Jun Liu

Daping Hospital

Xiang Zhang

Third Military Medical University

Yi Wu ( $\nabla$ wuy1979@tmmu.edu.cn )

Third Military Medical University

\section{Research Article}

Keywords: medical education, virtual anatomy, teaching mode, Chinese Visible Human, sectional anatomy

Posted Date: December 28th, 2020

DOl: https://doi.org/10.21203/rs.3.rs-120997/v1

License: (c) (i) This work is licensed under a Creative Commons Attribution 4.0 International License. Read Full License 


\section{Abstract}

Background: Education of human anatomy has always experienced many difficulties, including the lack of anatomical specimens and limitations imposed by anatomical dissection techniques that damage and change the shape and position of the anatomical structures.

Methods: A digital virtual anatomy system may be the solution to these difficulties. Based on highresolution sectional anatomical images from the Chinese Visible Human dataset, a virtual anatomy system was created. In total, 170 undergraduate students from the Third Military Medical University were divided into two groups, namely the combining virtual anatomy (CVA) group and the traditional anatomy (TA) group. The CVA group was taught using both the virtual anatomy system and the traditional anatomy course, while the TA group was taught using only the traditional course. After completing the course, the teaching outcomes were assessed by written and practical examinations, and the satisfaction levels of the students and teachers were also assessed with questionnaires.

Results: The examination scores and questionnaires showed that the CVA anatomy course provided a comfortable studying environment for medical students and greatly improved their self-learning ability, active thinking ability, 3D spatial thinking ability and interest in learning.

Conclusions: The teaching mode adding the virtual anatomy course with the traditional anatomy course is a new and effective way to advance the teaching of human anatomy, which is better than traditional dissection.

\section{Background}

Every year, large numbers of students enroll in medical schools in China [1]. In 2008, there were 159 medical schools and institutions with approximately 1.7 million students [2]. Traditional anatomical study has been used in medical schools for almost 100 years and still plays an integral role [3, 4]. In most Chinese medical schools, human anatomy courses mainly include cadaver dissection and reading anatomical textbooks and atlases [5]. However, some of shortcomings of dissection include the destructive nature of dissection, possible shortage and costs of procuring cadavers, storage and infrastructure to properly house the specimens, and the fumes associated with working in cadavericbased learning environments [6-8]. This may leave students with less time to spend on actual observing and studying human anatomy.

To lessen the limitations associated with the traditional anatomy courses, many medical schools in North America and Europe are using a virtual anatomy system (VAS) in the human anatomy curriculum to some extent [9-12].

Based on our previous study [13] and the Chinese Visible Human dataset, we and Shandong Digital Human Corporation (Digihuman, 2017, http://www.digihuman.com/) created a 3D interactive human anatomy study system, which included interactive 3D models and sectional anatomical images of 
human structures [14]. The Chinese Visible Human dataset has high-resolution sectional anatomical images that can be applied in many useful ways for both clinical anatomical research and anatomical and clinical medical education purposes $[3,6,13,15-17]$.

This VAS is a computer-driven approach to anatomical laboratory experiences that avoid those associated with cadaveric dissection [9]. This approach can stimulate study interest and improve the study initiative of students because of it has high quality 3D images, a comfortable environment, and easy operation without having to directly face a cadaver and inhale formalin vapors $[10,12,14]$.

It has controversial issue about use of the VAS in human anatomy courses in Chinese medical universities. Some people still remain skeptical about this approach because it is virtual and does not involve touching a real cadaver; it is also expensive, requires supercomputer capability and uses an artist's interpretation of anatomy [18]. Whether this teaching mode can improve active learning and problem-solving skills [19] and whether this mode can be adapted for the Chinese educational environment are still in dispute.

Therefore, in order to verify whether the VAS can replace the traditional anatomy course, or whether it should act as a complementary system to the traditional anatomy course, and whether this teaching mode combing virtual anatomy system and traditional anatomy teaching can promote active learning and improve learning efficiency. The authors used the VAS in anatomy courses taken by undergraduate students attending the Third Military Medical University; collected and analyzed the results of their written and practical examinations and the results of the satisfaction questionnaires, determining significance with 1-way independent sample t-tests.

\section{Methods}

\section{Virtual Anatomy System in Third Military Medical University}

With the help of Shandong Digital Human Corporation, the Third Military Medical University established a local network of VAS. Detailed information on the VAS is available at the website (http://www.digihuman.com/). The software can be viewed at http://www.digihuman.com/en. This VAS is online system, so one can access it whenever and wherever they want, which is an easy and convenient way for medical students to study human anatomy. A web version of the VAS was also created. In this version, teachers and students can use the software with any personal computer using the local area network of the university.

This VAS offers three learning modules, the male systematic anatomy module, the male regional anatomy module, and the female systematic anatomy module. In the systematic anatomy module, the main 10 category includes 9 anatomical systems including locomotor, alimentary, respiratory, urinary, male genital, vasculature, sensory, nervous and endocrine system (Fig. 1). In the male and the female regional anatomical modules, the catalogue includes the head, neck, thorax, abdomen, pelvis, vertebral column, upper limb, and lower limb region. 
The framework for these three modules has three parts, an anatomical structures catalogue and explanation section, a sectional anatomical image display section, and a 3D reconstructed model display section. In the catalogue area which occupies the left part of the interface, nearly all human organs are shown on the list, and they are included in the catalogue containing human system classifications (Fig. 1). The sectional anatomical image display area includes coronal, sagittal, and transverse sections. Students can move the scroll bar easily to display any plane of the human anatomy. In the 3D reconstructed model display area, students can easily translate, rotate, and amplify any of the 3D reconstructed models and then observe the 3D organ model in any direction and from any angle. Students can also make the superficial 3D structures semi-transparent to observe the deep structures. All parts and structures were mapped as realistic pictures, making them more accurate and attractive. Some vessels and bone markers can be observed on the surface of the bone (Fig. 2A, C, D). The muscle bellies, tendons, and muscle fibers can be observed on the muscle surface, and the orientation of the muscle fiber follow the orientation of the real muscle fiber (Fig. 2A, C). Additionally, the skin texture mapping used the texture of real human skin, making it appear more realistic on the screen, and the skin encompasses nearly all structures in the human body (Fig. 2B).

\section{Participating students}

In total, 170 undergraduate students in their first year at the Third Military Medical University were assigned to this study (Table 1). Their first semester consisted of a basic science curriculum, which included mathematics, physics, chemistry, and English. In subsequent semesters, medical students began their basic medical curriculum, which included systematic anatomy courses. Based on the scores obtained in previous medical compulsory courses, students were divided into a combining virtual anatomy (CVA) group and a traditional anatomy (TA) group, 66 students in the CVA group and 104 students in the TA group. According to the principle, these two group students have the same equivalent score. Because the limitation of website and teaching space of VAS, only 66 students take part in combing virtual anatomy system.

Before participation in the study, the teachers and the medical students were familiar with the study rules. The teachers gave participating students instructor materials including the important and complex anatomical structures which need to understand, comprehend and master. The medical students were military students, and they all strictly obeyed the principle of informed consent. Before the course, the average scores on the basic science curriculum were not significantly different between the CVA group and the TA group $(P<0.05)$. Each group had a group leader who was in charge of all members and collected the study information. The group leader was the communicator between students and teachers. To determine the students' progress, a pre-test including 20 multiple choice questions and 5 essay questions was administered before the beginning of the course, and the differences in test scores between the two groups were analyzed. This pre-knowledge test indicates the prior knowledge of the students and was verified by our authorship team. Table 1 shows the basic characteristics of the CVA and TA groups. 


\section{Teaching methods}

All students took typical courses in human regional anatomy. The regional anatomical courses in the Third Military University include basic theoretical courses (16 class hours) and practical courses (69 class hours). All the anatomical courses including theoretical and practical course will take one entire term which lasts 5 months. This course included lower limb, upper limb, thorax, abdomen, pelvic and perineum, head and neck dissection.

In the practical course of the CVA group, medical students studied human anatomy with VAS for $1 / 3$ class hours, for a total of 23 class hours, which accounted for one-third of the practical course. They studied the location, 3D shape and spatial relationship of human anatomy through translating, rotating and zooming the anatomy model in the VAS. They studied the location, 3D shape and spatial relationship of human anatomy through translating, rotating and zooming the anatomy model in the VAS. During the other two-thirds of the practical course, they studied human anatomy in the traditional mode including cadaver dissection and observation. In the practical course of the TA group, medical students studied human anatomy just through the traditional anatomy teaching mode including cadaver dissection and observation. Both in the CVA group and the TA group, medical students studied regional anatomy mainly by themselves and anatomical teacher worked as a tutor to help students to study human anatomy.

After the basic theoretical and practical course, all medical students had an additional 6 hours for review. In the review course, the CVA group students reviewed the information through the VAS, while the TA group students reviewed the information by observing specimens and reading reference books.

The teachers of the VAS course were trained before teaching the medical students. The courses for these two groups were launched synchronously. In the practical part of the course, all the medical students followed the guide to adhere to the same learning objectives. The VAS contains instructions that can be used to guide the user, and the user only needs to move the mouse or use the keyboard to easily operate the VAS.

\section{Evaluation methods}

Fourteen days after the last anatomical lesson, all students took an examination on regional anatomy, which included both written and practical portions. The written portion of the examination included 150 questions which was composed of single-choice questions, multiple-choice questions, and essay questions, and most of the questions were single-choice questions. Some of the questions in the pre-test examination was also repeated in this written examination.

The practical examination is a "bell-ringer" style practical examination. This examination was on the anatomical structure of a real cadaver that was present in the classroom, with labels on anatomical structures. The students wrote down the full name of each noted structure within a designated time limit. The medical students stayed at each station, each of which contained two anatomical structures, for only 
70 seconds. A full score on both the written examination and the practical examination was 100 points. In written examination, some questions were 0.5 point and some question was 1.0 point, and the full score of the written examination was also 100 points. The two groups of students were divided into five subgroups based on their scores on the examination. The score in Failure, Pass, Normal, Good and Excellent part is $<60,60-70,70-80,80-90,90-100$ separately. We compared the ratio of this subgroup in these two groups.

\section{Questionnaires administered to the students and teachers}

In order to evaluate the attention, 3D spatial thinking, interesting and satisfaction of the students studying human anatomy with the VAS, questionnaires were distributed to the students in the CVA group. The items in the questionnaire are listed in Table 2 (This table is placed at the end of the document text file). The questionnaires given to the students had 20 questions. After we drafted this questionnaire, 5 specialists examined and modified it.

The items were measured on a five-point Likert scale ranging from 1 to 5 as follows: 5 -strongly agree; 4agree; 3-undecided; 2-disagree; 1-strongly disagree. In addition, students had the opportunity to comment on the content of the VAS.

The eight teachers who participated in the CTA group were invited to complete a self-structured questionnaire which was composed of 10 questions adapted from the questionnaire in Singh's study (Table 3). In the studies by Singh and Tian, the authors designed the questions, and the students responded to questions according to the questionnaire table in the study $[2,20]$. The completed questionnaires were strictly anonymous.

\section{Statistical analysis}

Statistical Product and Service Solutions (SPSS) 13 (SPSS Inc., Chicago, IL, USA) was used for the statistical analyses. The examination scores for both the CVA group and the TA group were analyzed using a 2-sided independent samples t-test. Cohen's d calculation was used to indicate the standardized difference between two means of the CVA and the TA groups' examination. $\mathrm{P}<0.05$ was considered statistically significant. The analysis was conducted in a manner that prevents the identification of individuals.

\section{Results}

The average scores on the basic science curriculum (Fig 3) were not significantly different between the CVA group and the TA group $(p<0.05)$. In the CVA group, there were 51 male students and 13 female students, and the mean age was 19.1 years. In the TA group, there were 84 male students and 20 female students, and the mean age was 19.0 years. 


\section{Application of software by medical students}

The average pre-course score in the CVA group was $23.9 \pm 8.0$, and the average pre-course score in the TA group was $23.5 \pm 8.0$ (Fig 3). The results of the pre-course assessment indicated that there was no significant difference in preexisting knowledge between the two groups. After the completion of the anatomy course, the average score on the written examination of regional anatomy was $84.7 \pm 4.0$ for the CVA group and $76.3 \pm 4.6$ for the TA group (Fig 3). The results indicated that there was a significant difference between the mean scores for the CVA group and the TA group $(p<0.05)$.

In the practical examinations, the average score of the CVA group was $78.4 \pm 6.1$, while that of the TA group was $68.4 \pm 8.1$ (Fig 3). The score of the CVA group was significantly higher than that of the TA group $(P<0.05)$, and the difference in scores between the CVA group and the TA group was greater on the practical examination than on the written examination (Fig. 3).

By verifying the results of the written and practical examinations, teachers observed that some students in the CVA group received an excellent grade on both written exam and practical exam, while none of the TA group students earned an excellent grade on those examinations. There were more students with good grades in the CVA group than in the TA group on both written exam and practical exam, and there were fewer failing students in the CVA group than in the TA group. Therefore, more students performed better in the CVA group than in the TA group (Fig. 4).

\section{Analysis of student questionnaire}

The results of the student questionnaire evaluation are shown in Table2. Students declared a high level of satisfaction with the VAS (mean: 4.1 on the five-point Likert-scale). About the new combing teaching mode, and the CVA group students said that they found it very interesting, convenient and efficient (Table 2 Q1, Q2, Q3). Participants mentioned that the combination of cadaver dissection and 3D images improved their 3D understanding and retention (Table 2 Q4, Q5). The CVA teaching mode provided students with more information about anatomy and reinforced the communication between teachers and students (Table 2 Q9, Q10). VAS also helped the instructor to guide the course adequately and to some extent supplemented the traditional anatomy course (Table 2 Q15, Q18). Most students were not convinced that VAS could fully replace the traditional anatomy course (Table 2 Q16). As to whether VAS alone could provide more detailed information about complicated and abstract anatomical structures, many students remained neutral (Table $2 \mathrm{Q6}$ ).

The Cohen's $d$ of the practical examination between the CVA and TA groups was 0.5893 , while the Cohen's $d$ of the written examination between the CVA and TA groups was 0.9107 . This finding shows that the effect of the VAS was greater on the written examination than on the practical examination. Although the VAS is very important, it still cannot completely replace the TA with real dissection. 


\section{Analysis of teacher questionnaire}

Teachers declared a high level of satisfaction with the VAS (mean: 3.7 on the five-point Likert-scale) (Table 3). The functionality of the VAS and virtual anatomy teaching mode was evaluated. As shown in Table 3, the CVA courses were viewed as a scientific and interesting teaching approach to enhance undergraduate education (Table 3 Q1, Q4), providing a comfortable environment (Table 3 Q2) and selfdirected learning skills (Table 3 Q7) for undergraduate students. Most of teachers, like students, remained neutral as to whether VAS can clearly demonstrate abstract and complicated anatomy structures (Table 3 Q6). Although most teachers still doubted that VAS could provide very detailed anatomy information to undergraduate students (Table 3 Q5) and possibly replace the TA teaching mode (Table 3 Q9), most of them agreed that combining CVA with TA courses could replace the existing TA course (Table 3 Q10).

\section{Discussion}

Virtual anatomy is a new digital and virtual simulation technique to teach human anatomy [21-24], and it is a great supplement to traditional human anatomy studies. In a traditional cadaver dissection course, approximately 8-16 people use only one complete cadaver because of the scarcity of cadavers. Therefore, it is not always easy to rotate and transform the heavy cadaver frequently because at least 2-3 people are needed to move or rotate one complete cadaver (Table2 Q2). However, through vivid 3D interactive operation, it is a simple task to transform and rotate the virtual human organs in three-dimensional virtual space $[25,26]$ (Table2 Q1, 2). The final test scores obtained by students in the CVA group supported this view regarding the superiority of a combined teaching mode incorporating the VAS and the traditional dissection course. The results obtained from the questionnaires showed that most students preferred VAS, although both training modes have the same aim and provide the same anatomical information (Table2 Q1, 2). For most students, the VAS was interesting and facilitated and convenient to learn anatomy at the same time (Table2 Q1, 2). They were pleased with the attractive, high quality and interactive 3D anatomical models available through this system, which can provide them 3D spatial thinking ability (Table2 Q4, 5). Moreover, the VAS can store a large amount of data including 3D human organ models, sectional anatomy images, dissection videos and anatomy cartoon videos in small space (Table2 Q8, 9).

Although the TA group and the CVA group had the same study hours, the CVA course stimulated study interest and initiative, developed 3D thinking abilities, and improved knowledge acquisition and understanding [27], which was a very important aspect of the anatomy course (Table2 Q1, 3, 4). The medical students in the CVA group obtained higher examination scores and reported high scores on the questionnaire, which confirms the benefits of the CVA course including interesting, curiosity, anatomical relevance and satisfaction from the viewpoint of the students (Table2 Q1, 3, 4, 5). The 3D model allows medical students to understand human anatomy better and improves their level of knowledge of anatomy. The VAS can improve medical students' spatial ability through operation the 3D human model in the VAS (Table2 Q3) with translating, rotating and zooming the 3D models. Therefore, the CVA course 
which combined the VAS can raise more students' interesting, satisfaction, curiosity, environment comfort, 3D spatial thinking ability and study efficiency compared with the TA course. (Table2 Q9, 14, 20)

As a superior method of teaching anatomy, the VAS and the CVA course was well received by students, but the course which totally use 3D VAS cannot completely replace traditional dissection anatomy courses (Table2 Q16, Table3 Q9) [8, 28, 29]. The VAS provide the realistic anatomical structures, however, it lacks the sense of touch. If medical students want to be familiar with complicated and abstract anatomical structures, such as fascia and space, the virtual anatomy teaching mode alone may not be sufficient (Table2 Q6, 7, Table3 Q6, 8). To understand these abstract structures, medical students must touch them in a real cadaver before clinical work [29]. Students in the dissection room can also gain experience and skills because they are confronted with death, the need to respect the dead, and the opportunity to work as a team, which are all relevant skills for future doctors (Table2 Q16, Table3 Q8, 9). These might not be gained if students only have access to the VAS (Table2 Q11, Table3 Q5).

Cadavers can also offer students the opportunity to have a learning relationship with their "first patient" (https://www.mededportal.org/publication/9975/) [30-34]. Cadavers have individual difference [35] and also offer a complex and real biological view of what lies beneath the skin. The VAS simply cannot do this due to scan resolution, post-processing resolution, the skill of the artists and computer operators (Table2 Q4, 11, Table3 Q6). What VAS offers is a simplified 'model' view of the labeled constituent pieces of the pertinent anatomy [36, 37].

In general, the vast majority of students and teachers were satisfied with using this virtual anatomy system environment rather than studying in dissection rooms (Table2 Q12, 13, 19 Table3 Q3, 4), and they think the VAS changes the learning environment of the gross anatomy lab, and they need not to inhale formalin (Table3 Q2), and can dissect the digital cadaver repeatly and need not worry about the destroy and move the digital cadaver (Table2 Q2) [38].

\section{Conclusions}

The CVA course can be facilitated and convenient for medical students to learn anatomy, contained much anatomical information, activity thinking ability, environment comfort, 3D spatial thinking ability, study interest and study efficiency. However, the virtual anatomy course alone cannot fully replace the traditional anatomy course due to its lack of the sense of touch and dissection. Thus, the course combining the VAS with dissection should be considered as a new and effective way to teaching modern human anatomy, which can offset the shortage of the teachers and the cadaver. Most students and teacher like the VAS and the CVA course, although the VAS cannot replace the traditional dissection course.

\section{Abbreviations}


CVA : combining virtual anatomy; TA : traditional anatomy; CVH: Chinese visible human; VAS : virtual anatomy system; SPSS : Statistical Product and Service Solutions; 3D: three dimensions.

\section{Declarations}

\section{Acknowledgements}

We thank all the participants in this study who provided a clearer direction for medical education. We thank Shandong Digital Human Corporation for their technical assistance with this project.

\section{Author's contributions}

$\mathrm{CN}, \mathrm{FB}, \mathrm{WY}, \mathrm{LK}$ contributed to study design, data collection, data analysis, drafting of the manuscript. TL, $L Y, L N, Z S$ contributed to study design of the manuscript. All authors provided consent to publish this study to the BMC Medical Education journal. All authors read and approved the final version of the manuscript.

\section{Funding}

This work was supported by the Teaching Reform Project of Postgraduate in Chongqing (No. yjg183144), the National Natural Science Project (31771324 and 31671251).

\section{Availability of data and materials}

The datasets generated and/or analysed during the current study are not publicly available due the confidentiality agreements approved by the Academic Affairs Department, Third Military Medical University, but are available from the corresponding author on reasonable request.

\section{Ethics approval and consent to participate}

This study was approved by the Institutional Review Board at the Third Military Medical University (Date of signature is 2011.8.20) and all methods were carried out in accordance with the ethical standards laid down in the 1964 Declaration of Helsinki and its later amendments. Written informed consent for participation in the study was obtained from the participating students and teachers.

\section{Consent for publication}

Not applicable. 


\section{Competing interests}

The authors declare that they have no competing interests.

\section{Author details}

${ }^{1}$ Institute of Digital Medicine, Biomedical Engineering College, Third Military Medical University, Chongqing, China. ${ }^{2}$ Department of Dermatology, Southwest Hospital, Third Military Medical University, Chongqing, China. ${ }^{3}$ Department of Gastroenterology, Daping Hospital, Third Military Medical University, Chongqing, China.

\section{References}

1. Sun $\mathrm{W}, \mathrm{Wu} \mathrm{H}$, Wang L. Occupational stress and its related factors among university teachers in China. J Occup Health. 2011; 53: 280-286.

2. Tian Y, Xiao W, Li C, Liu Y, Qin M, Wu Y, Xiao L, Li H. Virtual microscopy system at Chinese medical university: an assisted teaching platform for promoting active learning and problem-solving skills. BMC Med Educ. 2014; 14: 74.

3. Zhang S-X, Heng P-A, Liu Z-J. Chinese visible human project. Clinical anatomy (New York, N Y ). 2006; 19: 204-215.

4. Zhang SX, Heng PA, Liu ZJ, Tan LW, Qiu MG, Li QY, Liao RX, Li K, Cui GY, Guo YL, Yang XP, Liu GJ, Shan JL, Liu JJ, Zhang WG, Chen XH, Chen JH, Wang J, Chen W, Lu M, You J, Pang XL, Xiao H, Xie YM. Creation of the Chinese visible human data set. Anat Rec B New Anat. 2003; 275: 190-195.

5. Wu Y, Zhang SX, Luo N, Qiu MG, Tan LW, Li QY, Liu GJ, Li K. Creation of the digital three-dimensional model of the prostate and its adjacent structures based on Chinese visible human. Surg Radiol Anat. 2010; 32: 629-635.

6. Wu Y, Luo N, Tan L, Fang B, Li Y, Xie B, Liu K, Chu C, Li M, Zhang S. Three-dimensional reconstruction of thoracic structures: based on Chinese Visible Human. Computational and mathematical methods in medicine. 2013; 795650.

7. Songur A, Ozen OA, Sarsilmaz M. The toxic effects of formaldehyde on the nervous system. Rev Environ Contam Toxicol. 2010; 203: 105-118.

8. Saltarelli AJ, Roseth CJ, Saltarelli WA. Human cadavers Vs. multimedia simulation: A study of student learning in anatomy. Anat Sci Educ. 2014; 7: 331-339.

9. Campbell B, Rosse C, Brinkley JF. The Virtual Anatomy Lab: a hands-on anatomy learning environment. Stud Health Technol Inform. 2001; 81: 85-87. 
10. Codd AM, Choudhury B. Virtual reality anatomy: is it comparable with traditional methods in the teaching of human forearm musculoskeletal anatomy? Anat Sci Educ. 2011; 4: 119-125.

11. Garg A. Virtual anatomy: New opportunities for education research. Acad Med. 1998; 73:1217-1218.

12. Palombi O, Pihuit A, Cani MP. 3D Modeling of branching vessels from anatomical sketches: towards a new interactive teaching of anatomy: Interactive virtual blackboard. Surg Radiol Anat. 2011; 33: 631-636.

13. Zhang SX, Heng PA, Liu ZJ, Tan LW, Qiu MG, Li QY, Liao RX, Li K, Cui GY, Guo YL, Yang XP, Liu GJ, Shan JL, Liu JJ, Zhang WG, Chen XH, Chen JH, Wang J, Chen W, Lu M, You J, Pang XL, Xiao H, Xie YM, Cheng JC. The Chinese Visible Human (CVH) datasets incorporate technical and imaging advances on earlier digital humans. J Anat. 2004; 204: 165-173.

14. Fang BJ, Wu Y, Chu C, Li Y, Luo N, Liu KJ, Tan LW, Zhang SX. Creation of a Virtual Anatomy System based on Chinese Visible Human data sets. Surg Radiol Anat. 2017; 39: 441-449.

15. Rong J, Wang Q, Liu K, Tan L, Ran X, Zhang S, Li Q, Han Y. A new atlas localization approach for subthalamic nucleus utilizing Chinese visible human head datasets. PloS one. 2013; 8: e57264.

16. Cheng G, Guo YL, Zhong CY, Tan LW, Zhang SX. Value of a virtual hepatic segment model in assisting in the ultrasonic localization of intrahepatic lesions. Chinese medical journal. 2013; 126 : 4417-4422.

17. Wu Y, Dabhoiwala NF, Hagoort J, Shan JL, Tan LW, Fang BJ, Zhang SX, Lamers WH. 3D Topography of the Young Adult Anal Sphincter Complex Reconstructed from Undeformed Serial Anatomical Sections. PLoS One. 2015; 10: e0132226.

18. Eldridge G Doubleday , Valerie D O'Loughlin, Alison F Doubleday. The virtual anatomy laboratory: usability testing to improve an online learning resource for anatomy education. Anat Sci Educ. 2011; 4(6):318-26.

19. Lian J, He F. Improved performance of students instructed in a hybrid PBL format. Biochemistry and molecular biology education : a bimonthly publication of the International Union of Biochemistry and Molecular Biology. 2013; 41: 5-10.

20. Singh A. Student performance and their perception of a patient-oriented problem-solving approach with audiovisual aids in teaching pathology: a comparison with traditional lectures. Adv Med Educ Pract. 2011; 2: 9-15.

21. Hew KF, Cheung WS. Use of three-dimensional (3D) immersive virtual worlds in K-12 and higher education settings: A review of the research. British Journal of Educational Technology. 2010; 41: 3355 .

22. Jarmon L, Traphagan T, Mayrath M. Understanding project-based learning in Second Life with a pedagogy, training, and assessment trio. Educational Media International. 2008; 45: 157-176.

23. Richardson A, Hazzard M, Challman SD, Morgenstein AM, Brueckner JK. A "Second Life" for gross anatomy: applications for multiuser virtual environments in teaching the anatomical sciences. Anat Sci Educ. 2011; 4: 39-43. 
24. Trelease RB. Anatomical informatics: Millennial perspectives on a newer frontier. Anat Rec. 2002; 269: 224-235.

25. Kim SH, Jang SH. Prediction of aphasia outcome using diffusion tensor tractography for arcuate fasciculus in stroke. AJNR Am J Neuroradiol. 2013; 34: 785-790.

26. Takano M, Komaki Y, Hikishima K, Konomi T, Fujiyoshi K, Tsuji O, Toyama Y, Okano H, Nakamura M. In vivo tracing of neural tracts in tiptoe walking Yoshimura mice by diffusion tensor tractography. Spine (Phila Pa 1976). 2013; 38: E66-72.

27. Brewer DN, Wilson TD, Eagleson R, de Ribaupierre S. Evaluation of neuroanatomical training using a 3D visual reality model. Studies in health technology and informatics. 2012; 173: 85-91.

28. Durham JA, Brettell S, Summerside C, McHanwell S. Evaluation of a virtual anatomy course for clinical undergraduates. Eur J Dent Educ. 2009; 13: 100-109.

29. Dyer GSM, Thorndike MEL. Quidne mortui vivos docent? the evolving purpose of human dissection in medical education. Academic Medicine. 2000; 75: 969-979.

30. Bay BH, Ling EA. Teaching of anatomy in the new millennium. Singapore Med J. 2007; 48: 182-183.

31. Bohl M, Francois W, Gest T. Self-guided clinical cases for medical students based on postmortem CT scans of cadavers. Clin Anat. 2011; 24:655-663.

32. Granger NA. Dissection laboratory is vital to medical gross anatomy education. Anatomical record Part B, New anatomist. 2004; 281: 6-8.

33. McLachlan JC, Bligh J, Bradley P, Searle J. Teaching anatomy without cadavers. Medical education. 2004; 38: 418-424.

34. Prakash, Prabhu LV, Rai R, D'Costa S, Jiji PJ, Singh G. Cadavers as teachers in medical education: knowledge is the ultimate gift of body donors. Singapore medical journal. 2007; 48: 186-189.

35. Moore CW, Wilson TD, Rice CL. Digital preservation of anatomical variation: 3D-modeling of embalmed and plastinated cadaveric specimens using uCT and MRI. Ann Anat. 2017; 209: 69-75.

36. Adams CM, Wilson TD. Virtual cerebral ventricular system: an MR-based three-dimensional computer model. Anat Sci Educ. 2011; 4: 340-347.

37. Sergovich A, Johnson M, Wilson TD. Explorable three-dimensional digital model of the female pelvis, pelvic contents, and perineum for anatomical education. Anat Sci Educ. 2010; 3: 127-133.

38. Hopkins R, Regehr G, Wilson TD. Exploring the changing learning environment of the gross anatomy lab. Acad Med. 2011; 86: 883-888.

\section{Tables}

Due to technical limitations, tables are only available as a download in the Supplemental Files section.

\section{Figures}




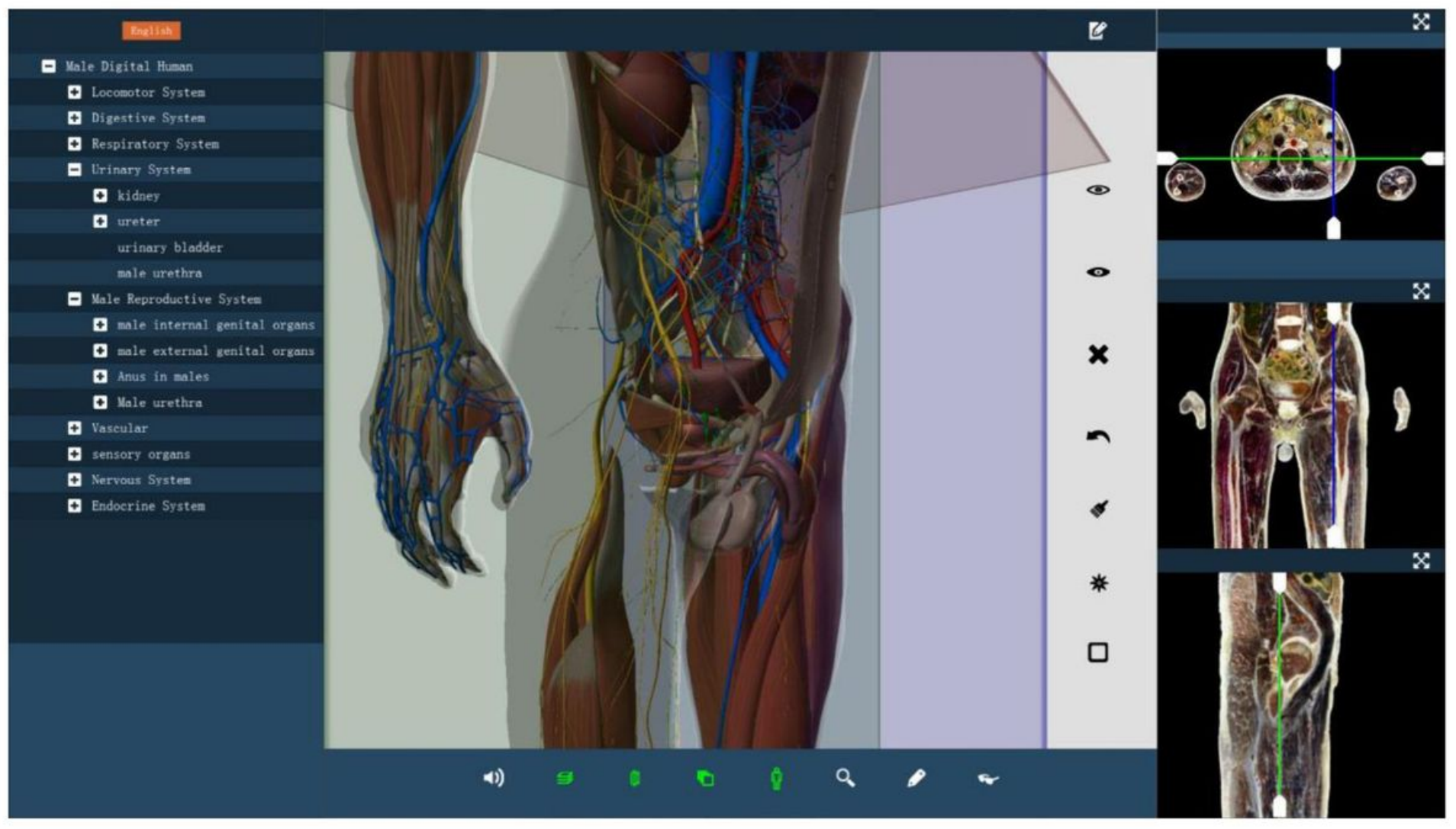

\section{Figure 1}

Interface for the male regional anatomy module in the Virtual Anatomy System. The left-hand screen is the catalogue of the human structure, the middle main screen is the 3D reconstruction of regional anatomy, and the right three panels are the transverse, coronal and sagittal sections based on $\mathrm{CVH}$ images. 

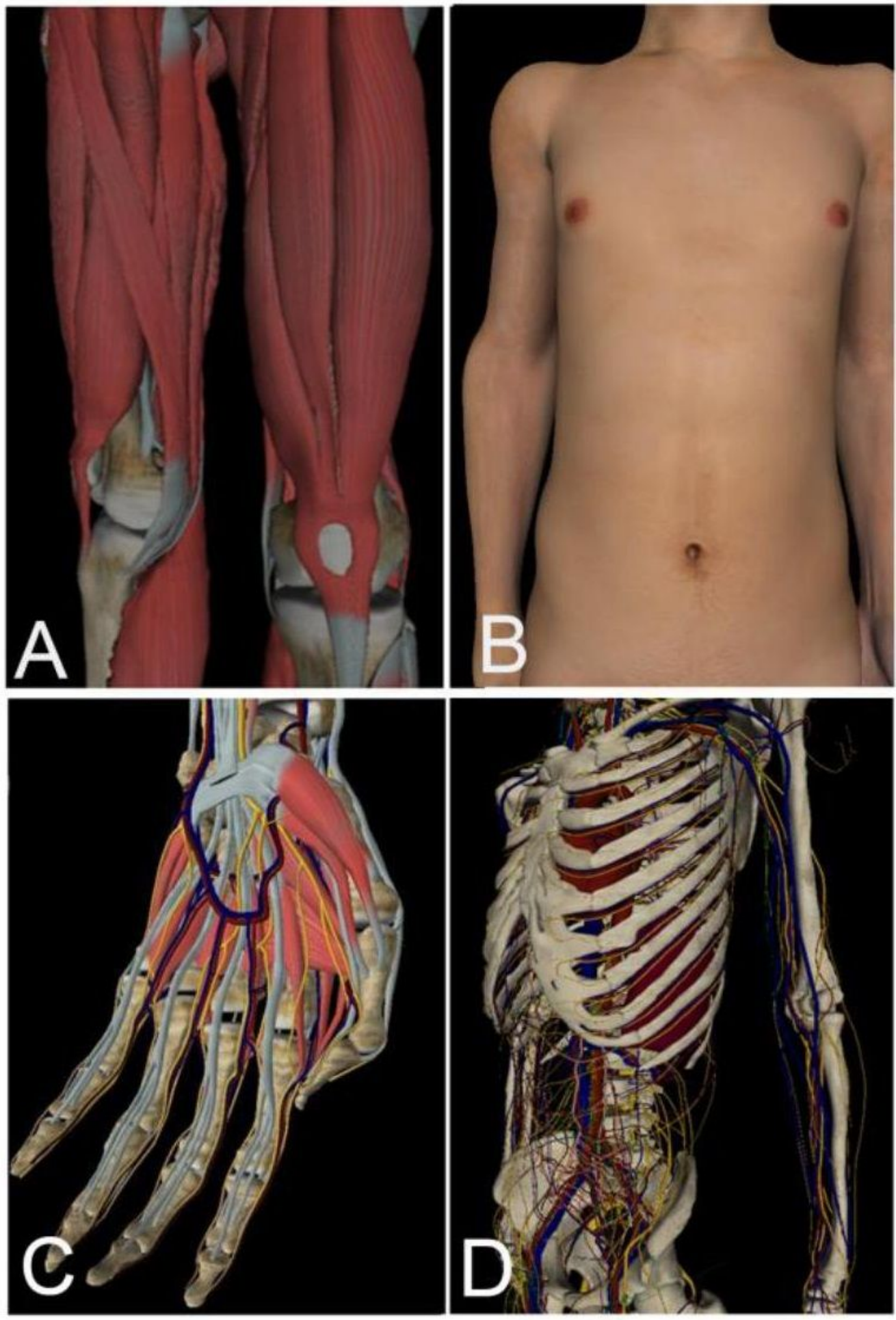

Figure 2

Three-dimensional human model display the human skeleton and muscles showing texture. (A) Thigh; (B) skin; (C) hand; (D) torso. 


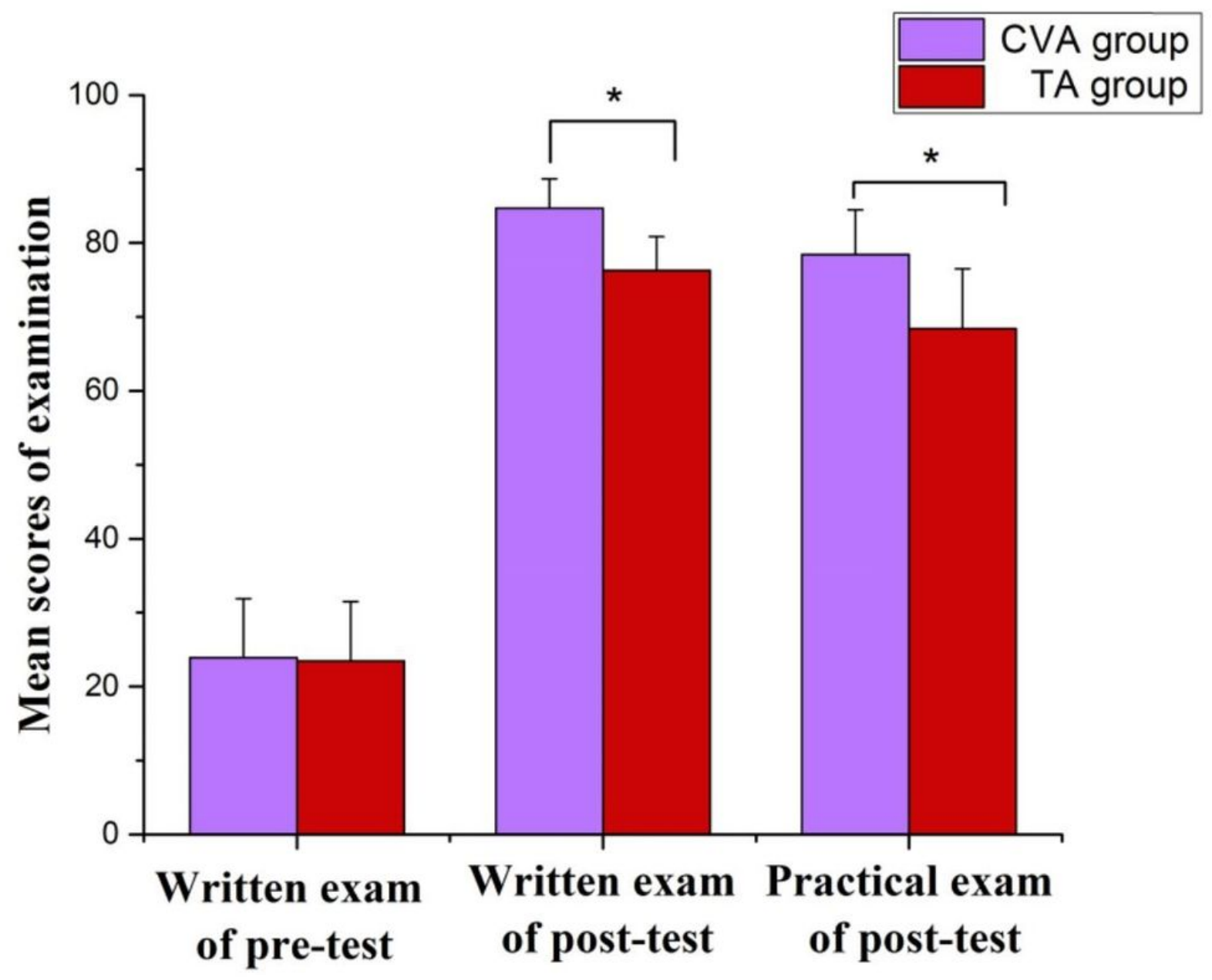

Figure 3

Mean examination scores $(X \pm S D)$ for the pre-test and post-tests on human anatomy. CVA group $(n=66)$ and TA group $(n=104)$. ${ }^{*}<0.05$. CVA: combining virtual anatomy; TA: traditional anatomy 


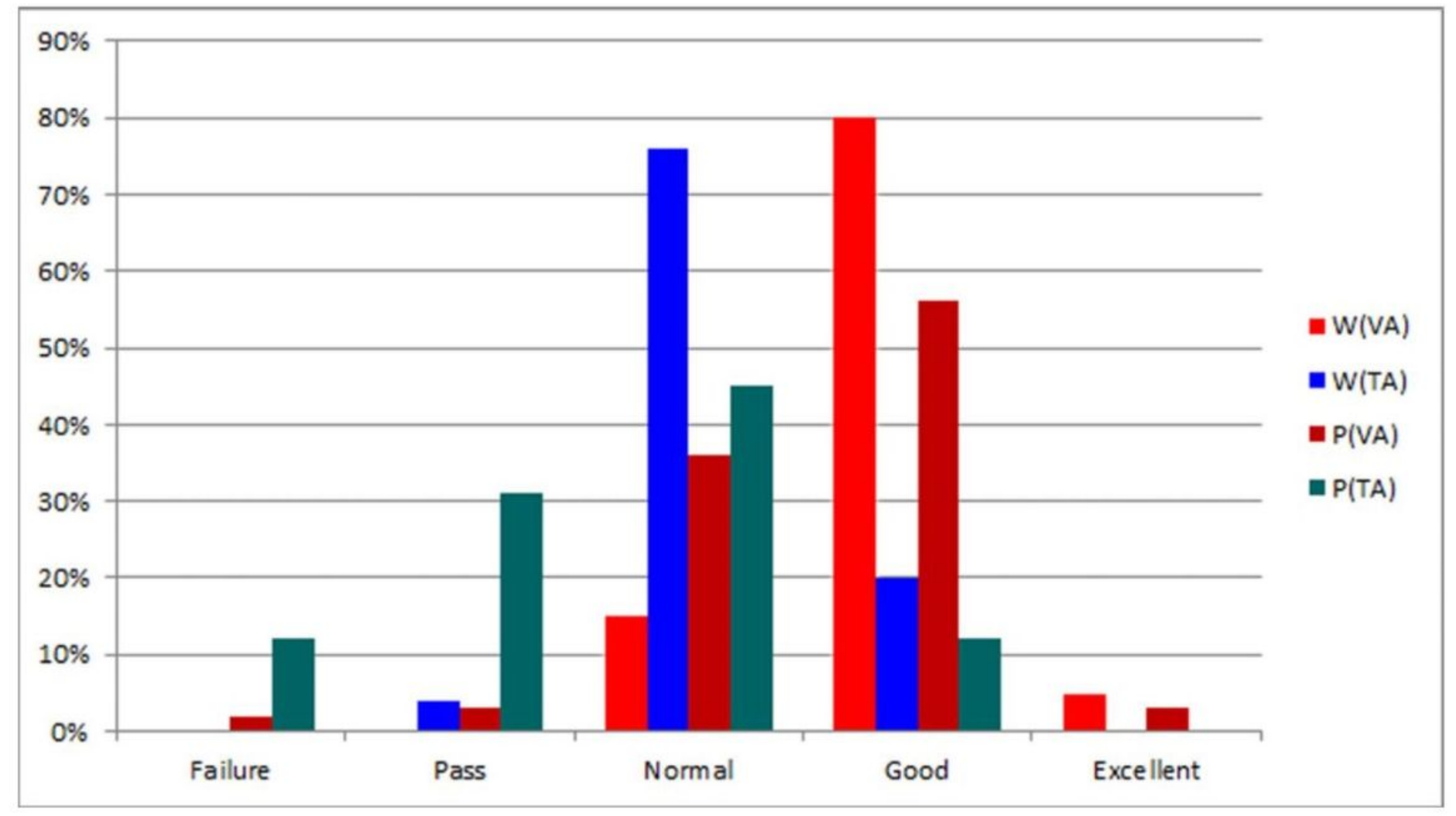

Figure 4

Grades earned on the examination by medical students in regional anatomy courses. W (VA): ratio of CVA group students in written exam. W (TA): ratio of TA group students in written exam. P (VA): ratio of CVA group students in practical exam. $\mathrm{P}(\mathrm{TA})$ : ratio of TA group students in practical exam.

\section{Supplementary Files}

This is a list of supplementary files associated with this preprint. Click to download.

- Tables.docx 